\title{
Occupational stress and its related factors among university teachers in Japan
}

\author{
Mika Kataoka ${ }^{1^{*}}$, Kazuhiro Ozawa $^{2}$, Masahito Tomotake ${ }^{1}$, Tetsuya Tanioka $^{1}$, Beth $_{\text {King }}{ }^{3}$ \\ ${ }^{1}$ Department of Nursing, Institute of Health Biosciences, The University of Tokushima Graduate School, Tokushima, Japan; \\ *Corresponding Author: mika3@tokushima-u.ac.jp \\ ${ }^{2}$ Gifu College of Nursing, Gifu, Japan \\ ${ }^{3}$ Christine E. Lynn College of Nursing, Florida Atlantic University, Boca Raton, USA
}

Received 29 December 2013; revised 31 January 2014; accepted 9 February 2014

Copyright (c) 2014 Mika Kataoka et al. This is an open access article distributed under the Creative Commons Attribution License, which permits unrestricted use, distribution, and reproduction in any medium, provided the original work is properly cited. In accordance of the Creative Commons Attribution License all Copyrights ¿ 2014 are reserved for SCIRP and the owner of the intellectual property Mika Kataoka et al. All Copyright (c) 2014 are guarded by law and by SCIRP as a guardian.

\section{ABSTRACT}

The purpose of this research was to investigate occupational stress and its related factors among university teachers in Japan. Questionnaire surveys were mailed to 924 university teachers in Japan with a response rate of $43.8 \%, N=405$. The General Health Questionnaire 28 (GHQ-28), Multidimensional Scale of Perceived Social Support (MSPSS), short Japanese version of brief Coping Orientation to Problems Experienced (COPE) and the Work Situation Questionnaires (WSQ) developed by the authors were administered to participants. Results indicated that university teachers had some mental health problems in relation to gender, professional position, conditions of taking paid leave, job satisfaction, job control, social support, and coping skills. These findings provide evidence that in order to improve the mental health of university, teachers need to take their paid leave freely. It is important to keep high their job satisfaction levels, job control levels, and social support. The results also indicated that the ineffective coping styles lead to poor mental health. In addition, the findings identified the necessity for support of female teachers and younger lecturers, who had a greater tendency toward poor mental health.

\section{KEYWORDS}

Occupational Stress; Mental Health; Japan; University Teachers

\section{INTRODUCTION}

Educators are a group with high stress [1,2], and in
Japan the mental health of teaching staff is becoming a serious issue. In 2011, the number of teaching staff in Japanese public primary, middle, and high schools who missed work due to mental disorders was 5274; comprising $62 \%$ of sick leave, as reported by the Ministry of Education, Culture, Sports, Science and Technology, 2011. This number declined in the last 2 years; however, it is 8 times what it was in 1979 when the survey began, and this serious state of circumstances continues. For this reason, researchers have conducted many studies [3-5] of primary, middle, and high school teaching staff regarding their mental health.

In contrast to primary and high schools, all of the university teaching staff performance reviews and promotions are directly related to their research results and teaching [6]. Also, work-related stress in university teaching staff is a notable feature globally due to the burdens of fixed-term systems and the acquisition of research funds [7] (America [8-10], UK [11-16], Australia [7,17], New Zealand [18,19], China [6], Nigerian [20], Malaysia [1]). Additionally, the teaching staff of Japanese universities are asked to fulfill roles at research institutions and regional contribution roles.

According to the Ministry of Education, Culture, Sports, Science and Technology in 2008, Japan's declining birth rate, has allowed the country to approach a state of affairs wherein almost all students can attend a university as long as they are not particular about which university they attend.

University students are adolescents who are characterized as a "generation with psychologically-distressing", and modern youths are becoming more and more inept at human relations. Identifying factors that impact the mental health of university teaching staff is a very important issue in occupational health [6]. 
A literature review identified some surveys conducted in Japan to study the mental health of university staff [21]. A survey that studied a nursing college whose teaching staff were mostly women [22], showed that university teaching staff are also affected by serious work-related stress. However, further research is needed in this area.

The purpose of this research is to clarify the relationship between work-related stress and the mental health of university teaching staff in Japan.

\section{METHODS}

\subsection{Subjects}

The survey questionnaire was sent to 924 university teachers in Japan, of which 405 were returned with a response rate of $43.8 \%$. Due to incomplete returns, data from 337 surveys were analyzed.

\subsection{Survey Methods}

The self-administered questionnaire survey was mailed, retuned and analyzed from November 2010 to January 2011.

\subsection{Instruments}

The following instruments were used for data collection.

1) Individual parameters surveyed were gender, age, professional position, and length of teaching experience.

2) The Work Situation Questionnaires (WSQ) developed by authors, consisted of questions related to working hours, hours of homework per week, conditions of taking paid leave, job satisfaction and job control level.

3) Mental health conditions were evaluated using a modified version of the Japanese General Health Questionnaire (GHQ-28) [23,24]. A score 6 or over was considered as poor mental well-being.

4) Social support perceived by the teachers was assessed using the Japanese version of Multidimensional Scale of Perceived Social Support (MSPSS) [25-28]. Total and subscores range from 1 to 7 , with higher scores suggesting greater levels of perceived social support.

5) The coping style of the teachers was assessed using the Japanese short version of brief Coping Orientation to Problems Experienced (COPE) [29-31]. Sub-scores range from 1 to 8 , with higher scores suggesting greater levels of used coping skills.

\subsection{Data Analysis}

Data were analyzed by analysis of variance (ANOVA), Tukey test, and Pearson correlation test $(\mathrm{p}<0.05)$, using IBM SPSS Statistics Version 20.0 for Windows.

\subsection{Ethical Considerations}

This research was approved by the University of Tokushima hospital clinical study Ethical Review Board (approval number 1032). No harm could be identified to the participants. Return of the survey implied consent by the participants. Participants were notified that privacy would be protected as only aggregate data would be utilized in reporting of findings.

\section{RESULTS}

\subsection{Demographic Data}

The subject s' characteristics were shown in Table 1.

\subsection{The Relationship between Mental Health Conditions and Individual Parameters}

The relationship between mental health conditions and gender identified that women scored significantly higher in all items-GHQ-28 total score ( $<0.001)$, and GHQ28 sub-scores: somatic symptoms $(\mathrm{p}<0.001)$, anxiety and insomnia ( $<<0.01)$, social dysfunction $(\mathrm{p}<0.05)$, and severe depression $(\mathrm{p}<0.05)$ and in professional positions, a significant difference was found in the somatic symptoms, with lecturers scoring significantly higher than professors $(\mathrm{p}<0.05)$, respectively (See Table 2 ).

However, significant correlation was not observed in the relationship between mental health conditions and age or length of teaching experience (See Table 3).

\subsection{The Relationship between Mental Health Conditions and the Work Situation}

There were significant differences between the conditions of taking paid leave, the GHQ-28 total score ( $<$ < 0.001 ), and the GHQ-28 sub-scores: somatic symptoms $(\mathrm{p}<0.01)$, anxiety and insomnia $(\mathrm{p}<0.001)$, social dysfunction $(\mathrm{p}<0.05)$. In the GHQ-28 total score $(\mathrm{p}<$ 0.001 ), and GHQ-28 sub-scores anxiety and insomnia (p $<0.001$ ) were significantly lower for those who could take paid leave at any time than those who could not, and in the GHQ-28 sub-scores: somatic symptoms ( $<<0.01$ ) and social dysfunction $(\mathrm{p}<0.05)$ were significantly lower for those who could take paid leave at any time than those who could not (See Table 4).

In the WSQ, a significant negative correlation was observed between level of job satisfaction and total GHQ28 score $(\mathrm{r}=-0.421: \mathrm{p}<0.001)$, the GHQ-28 sub-scores: somatic symptoms $(\mathrm{r}=-0.269$ : $\mathrm{p}<0.001)$, anxiety and insomnia $(\mathrm{r}=-0.333$ : $\mathrm{p}<0.001)$, social dysfunction $(\mathrm{r}=$ $-0.499: \mathrm{p}<0.001)$, and severe depression $(\mathrm{r}=-0.233$ : $\mathrm{p}$ $<0.001$ ), respectively. In the level of control over their jobs, a significant negative correlation was observed in total GHQ-28 score ( $r=-0.406$ : $\mathrm{p}<0.001)$, the GHQ-28 
Table 1. The characteristics of 337 subjects.

\begin{tabular}{|c|c|c|c|c|}
\hline Variables & & & $\mathrm{N}(\%)$ & Mean \pm SD \\
\hline \multirow[t]{9}{*}{ Individual Parameters } & Gender & Men & $270(80.1)$ & \\
\hline & & Women & 67(19.9) & \\
\hline & Age (yrs) & & & $44.0 \pm 9.7$ \\
\hline & Professional position & & & \\
\hline & & Professor & $101(30.0)$ & \\
\hline & & Associate professor & $52(15.4)$ & \\
\hline & & Lecture & 53(15.7) & \\
\hline & & Assistant & 131(38.9) & \\
\hline & Teaching experiences (yrs) & & & $15.6 \pm 10.2$ \\
\hline \multirow[t]{9}{*}{ Work Situation (WSQ) } & Working hours per week & & & $60.8 \pm 16.6$ \\
\hline & Homework & Yes & $230(68.2)$ & \\
\hline & & No & 107(31.8) & \\
\hline & Conditions of taking paid le & & & \\
\hline & & Always & $48(14.2)$ & \\
\hline & & Often & $136(40.4)$ & \\
\hline & & Seldom & $153(45.4)$ & \\
\hline & Job satisfaction level (\%) & & & $63.1 \pm 17.9$ \\
\hline & Job control level (\%) & & & $60.3 \pm 19.8$ \\
\hline \multirow[t]{5}{*}{ Mental Health (GHQ-28) } & Total score & & & $6.78 \pm 5.70$ \\
\hline & & Somatic symptoms & & $2.62 \pm 2.23$ \\
\hline & & Anxiety and insomnia & & $2.36 \pm 2.01$ \\
\hline & & Social dysfunction & & $1.21 \pm 1.60$ \\
\hline & & Severe depression & & $0.59 \pm 1.42$ \\
\hline \multirow[t]{4}{*}{ Social Support (MSPSS) } & Total score & & & $5.26 \pm 1.05$ \\
\hline & & Family subscale & & $5.61 \pm 1.18$ \\
\hline & & Significant other subscale & & $5.34 \pm 1.20$ \\
\hline & & Friends subscale & & $4.82 \pm 1.20$ \\
\hline \multirow[t]{14}{*}{ Coping styles (COPE) } & & Self-distraction & & $4.66 \pm 1.29$ \\
\hline & & Active coping & & $5.68 \pm 1.02$ \\
\hline & & Denial & & $2.60 \pm 0.88$ \\
\hline & & Substance use & & $3.48 \pm 1.65$ \\
\hline & & Use of emotional support & & $4.61 \pm 1.36$ \\
\hline & & Use of instrumental support & & $4.89 \pm 1.31$ \\
\hline & & Behavioral disengagement & & $3.59 \pm 1.02$ \\
\hline & & Venting & & $4.40 \pm 1.20$ \\
\hline & & Positive reframing & & $5.24 \pm 1.18$ \\
\hline & & Planning & & $6.12 \pm 1.03$ \\
\hline & & Humor & & $4.02 \pm 1.32$ \\
\hline & & Acceptance & & $6.05 \pm 0.93$ \\
\hline & & Religion & & $3.00 \pm 1.13$ \\
\hline & & Self-blame & & $4.28 \pm 1.28$ \\
\hline
\end{tabular}

Work Situation Questionnaires (WSQ), General Health Questionnaire (GHQ-28), Multidimensional Scale of Perceived Social Support (MSPSS), brief Coping Orientation to Problems Experienced (COPE), and Standard deviation (SD).

sub-scores: somatic symptoms $(r=-0.294: \mathrm{p}<0.001)$, anxiety and insomnia $(\mathrm{r}=-0.336: \mathrm{p}<0.001)$, and social dysfunction $(\mathrm{r}=-0.442$ : $\mathrm{p}<0.001)$, respectively (See, Table 5).

\subsection{The Relationship between Mental Health Conditions, Social Support, and Coping Styles}

Analysis of the relationship between the mental health conditions and social support, revealed a significant neg- ative correlation between the GHQ-28 total score and the total score of MSPSS $(r=-0.267: \mathrm{p}<0.001)$ and the MSPSS subscales: family subscale $(\mathrm{r}=-205: \mathrm{p}<0.001)$, significant others subscale $(\mathrm{r}=-267: \mathrm{p}<0.001)$, and friends subscale $(r=-0.232$ : $p<0.001)$, respectively. There was also a negative correlation observed between social dysfunction of GHQ-28 subscale and support of significant others the MSPSS subscale $(r=-0.318$ : $\mathrm{p}<$ 0.001).

Analysis between the mental health conditions and 
Table 2. The relationship between GHQ-28, gender and professional positions.

\begin{tabular}{|c|c|c|c|c|c|}
\hline GHQ-28 & Total score & Somatic symntoms & Anxiety and insomni & Social dvsfunction & Severe denression \\
\hline (N) & 10lai Scule & 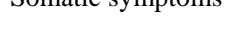 & 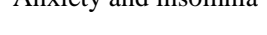 & - & 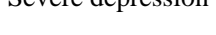 \\
\hline Gender $^{a)}$ & & & & & \\
\hline Men (270) & $6.21 \pm 5.597^{* * *}$ & $2.39 \pm 2.227^{* * * *}$ & $2.20 \pm 2.047^{* * *}$ & $1.10 \pm 1.507^{*}$ & $0.51 \pm 1.387^{*}$ \\
\hline Women (67) & $9.10 \pm 5.61$ & ل $3.55 \pm 2.04$ & $3.00 \pm 1.74$ & لـ 1.92 ـ 1.66 & لـ $0.90 \pm 1.56$ \\
\hline F-value (P-value) & $14.42\left({ }^{* * *}\right)$ & $15.07\left({ }^{* * *}\right)$ & $8.63\left(^{* *}\right)$ & $6.58\left(^{*}\right)$ & $3.94\left(\left(^{*}\right)\right.$ \\
\hline Professional position ${ }^{\text {b) }}$ & & & & & \\
\hline Professor (101) & $5.87 \pm 5.62$ & $2.14 \pm 2.057^{*}$ & $2.35 \pm 2.21$ & $1.00 \pm 1.46$ & $0.39 \pm 1.22$ \\
\hline Associate professor (52) & $6.23 \pm 5.57$ & $2.94 \pm 2.52$ & $1.73 \pm 1.79$ & $1.12 \pm 1.62$ & $0.44 \pm 1.16$ \\
\hline Lecturer (53) & $7.92 \pm 6.30$ & $3.15 \pm 2.38$ & $2.49 \pm 1.88$ & $1.43 \pm 1.77$ & $0.85 \pm 1.78$ \\
\hline Assistant (131) & $7.24 \pm 5.49$ & $2.66 \pm 2.14$ & $2.57 \pm 1.95$ & $1.32 \pm 1.63$ & $0.69 \pm 1.49$ \\
\hline F-value (P-value) & 2.04 (N.S.) & $2.99\left({ }^{*}\right)$ & 2.29 (N.S.) & 1.19 (N.S.) & 1.71 (N.S.) \\
\hline
\end{tabular}

Mean \pm SD, ${ }^{*} \mathrm{p}<0.05,{ }^{* *} \mathrm{p}<0.01,{ }^{* * *} \mathrm{p}<0.001$, N.S. $=$ Not Significant. ${ }^{\text {a) }}$ ANOVA, and ${ }^{\mathrm{b})}$ ANOVA with Tukey test.

Table 3. Correlation between the GHQ-28, age, and length of teaching experience.

\begin{tabular}{llllll}
\hline GHQ-28 & Total score & Somatic symptoms & Anxiety and insomnia & Social dysfunction & Severe depression \\
\hline Age (yrs) & $-0.112^{*}$ & $-0.152^{* *}$ & -0.043 & -0.051 & -0.093 \\
Teaching experiences (yrs) & -0.084 & $-0.113^{*}$ & -0.018 & -0.059 & -0.068 \\
\hline
\end{tabular}

${ }^{*} \mathrm{p}<0.05,{ }^{* *} \mathrm{p}<0.01$. Pearson correlation coefficient.

Table 4. Correlation between the GHQ-28, Homework, and conditions of taking paid leave.

\begin{tabular}{|c|c|c|c|c|c|}
\hline GHQ-28 & \multirow{2}{*}{ Total score } & \multirow{2}{*}{ Somatic symptoms } & \multirow{2}{*}{ Anxiety and insomnia } & \multirow{2}{*}{ Social dysfunction } & \multirow{2}{*}{ Severe depression } \\
\hline$(\mathrm{N})$ & & & & & \\
\hline \multicolumn{6}{|l|}{ Homework $^{\text {a) }}$} \\
\hline No (107) & $6.30 \pm 5.77$ & $2.30 \pm 2.30$ & $2.19 \pm 1.96$ & $1.21 \pm 1.67$ & $0.61 \pm 1.45$ \\
\hline Yes (230) & $7.01 \pm 5.67$ & $2.77 \pm 2.19$ & $2.44 \pm 2.03$ & $1.21 \pm 1.58$ & $0.58 \pm 1.40$ \\
\hline F-value (P-value) & 1.13 (N.S.) & 3.32 (N.S.) & 1.19 (N.S.) & 0.002 (N.S.) & 0.03 (N.S.) \\
\hline \multicolumn{6}{|c|}{$\begin{array}{l}\text { Conditions of taking } \\
\text { paid leave }\end{array}$} \\
\hline Always (48) & $4.17 \pm 3.86]^{* * * *}$ & $1.73 \pm 1.977^{* *}$ & $1.35 \pm 1.547^{*}$ & $0.79 \pm 0.977^{*}$ & $0.29 \pm 1.03$ \\
\hline Often (136) & $6.51 \pm 5.64$ Ј & $2.57 \pm 2.29$ & $2.25 \pm 1.91$ & $1.07 \pm 1.62$ & $0.63 \pm 1.44$ \\
\hline Seldom (153) & $7.84 \pm 5.97$ & $2.95 \pm 2.20$ & $2.78 \pm 2.11$ & $1.47 \pm 1.71$ & $0.65 \pm 1.51$ \\
\hline F-value (P-value) & $8.19\left(^{* * *}\right)$ & $5.64\left(^{* *}\right)$ & $10.04\left({ }^{* * *}\right)$ & $4.28\left(^{*}\right)$ & 1.22 (N.S.) \\
\hline
\end{tabular}

Mean \pm SD, ${ }^{*} \mathrm{p}<0.05,{ }^{* *} \mathrm{p}<0.01,{ }^{* * *} \mathrm{p}<0.001$. N.S. $=$ Not Significant. ${ }^{\text {a) }}$ ANOVA, ${ }^{\text {b) }}$ ANOVA with Tukey test.

Table 5. Correlation between the GHQ-28, working hours, job satisfaction and control levels.

\begin{tabular}{lccccc}
\hline GHQ-28 (WSQ) & Total score & Somatic symptoms & Anxiety and insomnia & Social dysfunction & Severe depression \\
\hline Working hours & 0.049 & 0.075 & 0.064 & 0.016 & -0.028 \\
Job satisfaction level & $-0.421^{* * *}$ & $-0.269^{* * *}$ & $-0.333^{* * *}$ & $-0.499^{* * *}$ & $-0.233^{* * * *}$ \\
Job control level & $-0.406^{* * *}$ & $-0.294^{* * *}$ & $-0.336^{* * *}$ & $-0.442^{* * *}$ & $-0.153^{* *}$ \\
\hline
\end{tabular}

${ }^{* *} \mathrm{p}<0.01,{ }^{* * *} \mathrm{p}<0.001$. Pearson correlation coefficient.

coping styles, identified correlations between the GHQ28 total score and the sub score of COPE: self-distraction $(\mathrm{r}=0.254: \mathrm{p}<0.001)$, substance use $(\mathrm{r}=0.246: \mathrm{p}<$ $0.001)$, behavioral disengagement $(\mathrm{r}=0.226$ : $\mathrm{p}<0.001)$, and self-blame $(r=330: p<0.001)$. Also, there was a correlation between anxiety and insomnia of the GHQ sub score and the self-blame of the COPE $(r=0.303$ : $p<$ 0.001) (See Table 6).

\section{DISCUSSION}

The subjects' average mean total score for mental health conditions on the GHQ-28 was $6.78 \pm 5.7$ points for their mental health conditions. This indicates a somewhat unhealthy group. All of the subscale scores of somatic symptoms, anxiety and insomnia, social dysfunction, and severe depression were higher in these subjects than the point average of a healthy person in Japan [24]. 
Table 6. Correlation between the GHQ-28, social support, and coping styles.

\begin{tabular}{|c|c|c|c|c|c|}
\hline GHQ-28 & Total score & Somatic symptoms & Anxiety and insomnia & Social dysfunction & Severe depression \\
\hline \multicolumn{6}{|l|}{ Social Support (MSPSS) } \\
\hline Total Score & $-0.267^{* * *}$ & $-0.119^{*}$ & $-0.202^{* * *}$ & $-0.286^{* * *}$ & $-0.275^{* * *}$ \\
\hline Family & $-0.205^{* * *}$ & -0.084 & $-0.165^{* *}$ & $-0.188^{* *}$ & $-0.245^{* * *}$ \\
\hline Significant others & $-0.267^{* * *}$ & $-0.125^{*}$ & $-0.180^{* *}$ & $-0.318^{* * * *}$ & $-0.260^{* * *}$ \\
\hline Friends & $-0.232^{* * *}$ & -0.105 & $-0.187^{* *}$ & $-0.249^{* * *}$ & $-0.220^{* * * *}$ \\
\hline \multicolumn{6}{|l|}{ Coping styles (COPE) } \\
\hline Self-distraction & $0.254^{* * *}$ & $0.219^{* * *}$ & $0.214^{* * *}$ & $0.184^{* *}$ & $0.166^{* *}$ \\
\hline Active coping & -0.007 & 0.040 & 0.051 & $-0.109^{*}$ & -0.039 \\
\hline Denial & 0.104 & 0.096 & 0.055 & 0.052 & $0.129^{*}$ \\
\hline Substance use & $0.246^{* * * *}$ & $0.135^{* *}$ & $0.242^{* * * *}$ & $0.197^{* * *}$ & $0.209^{* * *}$ \\
\hline Use of emotional support & 0.079 & $0.129^{*}$ & $0.126^{*}$ & -0.031 & -0.028 \\
\hline Use of instrumental support & -0.023 & 0.058 & 0.022 & -0.087 & $-0.117^{*}$ \\
\hline Behavioral disengagement & $0.226^{* * *}$ & $0.174^{* *}$ & $0.196^{* * *}$ & $0.154^{* *}$ & $0.181^{* *}$ \\
\hline Venting & $0.136^{*}$ & $0.166^{* *}$ & $0.160^{* *}$ & 0.053 & -0.002 \\
\hline Positive reframing & 0.056 & 0.053 & 0.034 & 0.025 & 0.067 \\
\hline Planning & -0.0001 & 0.086 & 0.003 & -0.059 & -0.073 \\
\hline Humor & 0.086 & $0.118^{*}$ & 0.081 & 0.026 & 0.016 \\
\hline Acceptance & 0.032 & 0.078 & 0.084 & -0.048 & -0.061 \\
\hline Religion & $0.121^{*}$ & $0.119^{*}$ & $0.136^{*}$ & 0.074 & 0.023 \\
\hline Self-blame & $0.330^{* * * *}$ & $0.214^{* * *}$ & $0.303^{* * * *}$ & $0.236^{* * *}$ & $0.290^{* * *}$ \\
\hline
\end{tabular}

${ }^{*} \mathrm{p}<0.05,{ }^{* *} \mathrm{p}<0.01,{ }^{* * *} \mathrm{p}<0.001$. Pearson correlation coefficient.

The research conducted on targeted university teaching staff in nursing colleges in of Japan $[21,32]$ indicated that university teaching staff is mentally unhealthy. These findings suggest that improvement of the mental health conditions of university teaching staff in Japan is an issue.

The research findings in this survey indicate that the following factors influenced mental health conditions; gender, professional position, conditions of taking paid leave, level of job satisfaction and job control, social support and coping style. Women scored significantly higher in all GHQ-28 items (total, and sub-scores: somatic symptoms, anxiety and insomnia, social dysfunction, and severe depression). This is the same pattern as the research on university teaching staff [20] and the research on nursing colleges with a large number of female teaching staff [33]. Furthermore, in professional positions, lecturers scored significantly higher than professors on somatic symptoms. These results suggest that the lecturer position and young age are risk conditions that cause stress making it more likely to evoke somatic symptoms. The ease of taking paid leave has an influence on all scores except severe depression. Higher levels of job satisfaction and job control influenced the lower scores in the GHQ total score, and GHQ-28 sub-scores: somatic symptoms, anxiety and insomnia, and social dysfunction.

In Karasek's Demand/Control model [34], the level of demand required by the job and control are said to be essential. Japanese research [35], which used Karasek's model for an analysis, reported that it was more effective to improve the degree of job control than degree of bur- den to reduce psychological stress reactions and improve job satisfaction. Similar to this study, previous studies targeting teaching staff in the UK $[15,16]$ showed that educators' jobs were affected by a sense that they did not control their jobs.

Therefore, it is important to provide a sense of job control to university teaching staff in order to improve mental health conditions. On the other hand, since the work hours and whether the educator did or did not work at home had no influence, on mental health conditions, the ability of the employee to freely take paid leave of their own volition is essential to maintain mental health. Regarding social support, the total GHQ-28 scores and the MSPSS overall score as well as the subscales showed a negative correlation. This indicated that in order to be mentally healthy it is necessary to utilize social support.

The coping style used by teachers showed a correlation of the GHQ-28 total score with the COPE: self-distraction, substance use, behavioral disengagement, and self-blame. It was generally considered that proactive coping leads to mental and physical health [36]. However, many stressors at the workplace are things that cannot be resolved by one's own efforts, and it was reported [37] that there is little coping done toward proactively resolving them. In this research, regarding coping, which influences mental health, it was assumed the likely that rather than the proactive utilization of coping, the passive use of coping styles was used more than the proactive style. This same tendency was found in research targeting assistants [33] and research targeting computer engineers [38]. 
The findings of this study indicate the need to release workers' stress, as for measures to decrease against occupational stress in university teaching staff, especially women. Measures to increase job control, and utilization of paid leave should be considered.

\section{LIMITATIONS}

The subjects in this research were one university, so generalization of the results would be limited. In the future, surveys which target a greater number of university teaching staff are desirable.

\section{CONCLUSION}

Authors formulated a hypothesis about a serious mental health issue of teaching staff caused by the outcomes of university teaching staff performance reviews in Japan. Results indicated that university teachers had some mental health problems in relation to gender, professional position, conditions of taking paid leave, job satisfaction, job control, social support, and coping skills. These findings provide evidence that in order to improve the mental health of university, teachers need to take their paid leave freely. It is important to keep high their job satisfaction levels, job control levels, and social support. The results also indicated that the ineffective coping styles lead to poor mental health. In addition, the findings identified the necessity for support of female teachers and younger lecturers, who had a greater tendency toward poor mental health.

\section{ACKNOWLEDGEMENTS}

The authors wish to thank the University of Tokushima Graduate School and its staff for their cooperation and assistance in undertaking this study.

\section{REFERENCES}

[1] Ahsan, N., Abdullah, Z., Fie, D.Y.G. and Alam, S.S. (2009) A study of job stress on job satisfaction among university staff in Malaysia: Empirical Study. European Journal of Social Sciences, 8, 121-131.

[2] Gary, W.B. (2012) A Discussion of the mental Health of public school teachers. International Journal of Business, Humanities and Technology, 2, 184-191.

[3] Kikuoka, H. (2007) Stress conditions and depressive tendencies in public school teaching staff. Job Stress Research, 14, 179-182.

[4] Nagai, M., Tsuchiya, K., Toulopoulou, T. and Takei, N. (2007) Poor mental health associated with job dissatisfaction among School Teachers in Japan. Journal of Occupational Health, 49, 515-522. http://dx.doi.org/10.1539/joh.49.515

[5] Shimizu, M., Wada, K., Wang, G., Kawashima, M., Yoshino, Y., Sakaguchi, H., Ohta, H., Miyaoka, H. and Ai- zawa, Y. (2011) Factors of working conditions and prolonged fatigue among teachers at public elementary and junior high Schools. Industrial Health, 49, 434-442. http://dx.doi.org/10.2486/indhealth.MS1206

[6] Sun, W., Wu, H. and Wang, L. (2011) Occupational stress and its related factors among university teachers in china. Journal of Occupational Health, 53, 280-286. http://dx.doi.org/10.1539/joh.10-0058-OA

[7] Winefield, H. and Jarrett, R. (2001) Occupational stress in university staff. International Journal Stress Management, 8, 285-298. http://dx.doi.org/10.1023/A:1017513615819

[8] Gmelch, W.H., Wilke, P.K. and Lovrich, N.P. (1986) Dimensions of stress among university faculty: Factoranalytic results from a national study. Research in Higher Education, 24, 266-286. http://dx.doi.org/10.1007/BF00992075

[9] Blix, G., Cruise, R.J., Mitchell, B.M. and Blix, G.G. (1994) Occupational stress among university teachers. Educational Research, 36, 157-169. http://dx.doi.org/10.1080/0013188940360205

[10] Richard, G.V. and Krieshok, T.S. (1989) Occupational stress, strain and coping strategies in university faculty. Journal of Vocational Behavior, 34, 117-132. http://dx.doi.org/10.1016/0001-8791(89)90068-7

[11] Abouserie, R. (1996) Stress, coping strategies and job satisfaction in university academic staff. Educational Psychology, 16, 49-56. http://dx.doi.org/10.1080/0144341960160104

[12] Bradley, J. and Eachus, P. (1995) Occupational stress within a U.K. higher education Institution. International Journal of Stress Management, 2, 145-158. http://dx.doi.org/10.1007/BF01740300

[13] Daniels, K. and Guppy, A. (1992) Control, informationseeking preferences, occupational stressors and psychological well-being. Work and Stress, 6, 347-353. http://dx.doi.org/10.1080/02678379208259965

[14] Wilkinson, J. and Joseph, S. (1995). Burnout in university teaching staff. The Occupational Psychologist, 27, 4-7.

[15] Tytherleigh, M.Y., Webb, C., Cooper, C.L. and Ricketts, C. (2001) Occupational stress in UK higher education institutions: A comparative study of all staff categories. Higher Education Research \& Development, 24, 41-61. http://dx.doi.org/10.1080/0729436052000318569

[16] Kinman, G. (2001) Pressure points: A review of research on stressors all strains in UK academics. Educational Psychology, 21, 473-492. http://dx.doi.org/10.1080/01443410120090849

[17] Gilespie, N.A., Walsh, M., Winefield, A.H., Dua, J. and Stough, C. (2001) Occupational stress in universities: Staff perceptions of the causes, consequences and moderators of stress. Work \& Stress, 15, 53-72.

[18] Boyd, S. and Wylie, C. (1994) Workload and stress in New Zealand Universities. New Zealand Council for Educational Research and the Association of University Staff of New Zealand, 114.

[19] Chalmers (1998) Workload and stress in New Zealand Universities in 1998. A follow-up to the 1994 study. New 
Zealand Council for Educational Research. http://www.nzcer.org.nz/system/files/5642.pdf

[20] Archibong, I.A., Bassey, A.O.G. and Effiom, D.O. (2010) Occupational stress sources among university academic staff. European Journal of Educational Studies, 2, 217225.

[21] Nishimura, Y., Iwasa, Y., Tanaka, Y., Fujii, K. and Takayama, M. (2010) Mental health survey of university staff in 2008. The Bulletin of Keio University Health Center, 28, 27-32.

[22] Kataoka, M., Ozawa, K., Ichie, K. and Iwamitsu, Y. (2008) The relationship between burnout, individual parameters, teaching aptitude and job satisfaction among research associates in college of nursing. Journal of Japan Society of Nursing Research, 31, 67-74.

[23] Goldberg, D.P. and Hillier, V.F. (1979) A scaled version of the General Health Questionnaire. Psychological Medicine, 9, 139-145. http://dx.doi.org/10.1017/S0033291700021644

[24] Nakagawa, Y. and Dibo, I. (1985) The General Health Questionnaire by Goldberg, D.P. Nihon Bunka Kagakusya.

[25] Dahlem, N., Zimet, G. and Walker, R. (1991) The multidimensional scale of perceived social support: A confirmation study. Journal of Clinical Psychology, 47, 756761. http://dx.doi.org/10.1002/1097-4679(199111)47:6<756:: AID-JCLP2270470605>3.0.CO;2-L

[26] Zimet, G.D., Dahlem, N.W., Zimet, S.G. and Farley, G.K. (1988) The multidimensional scale of perceived social support. Journal of Personality Assessment, 52, 30-41. http://dx.doi.org/10.1207/s15327752jpa5201_2

[27] Zimet, G.D., Powell, S.S., Farley, G.K., Werkman, S. and Berkoff, K. (1990) Psychometric characteristics of the multidimensional scale of perceived social support. Journal of Personality Assessment, 55, 610-617.

[28] Iwasa, H., Gondo, Y., Masui, Y., Inagaki, H., Kawai, C., Otsuka, R., Ogawa, M., Takayama, M., Imuta, H. and Suzuki, T. (2007) Reliability and validity of "Social Support Scale”, Japanese language edition-Investigation targeting middle and old age. Indicators of Social Welfare, 54, 26-33.

[29] Carver, C.S. (1997) You want to measure coping but your protocol's too long: Consider the brief COPE. International Journal of Behavioral Medicine, 4, 92-100. http://dx.doi.org/10.1207/s15327558ijbm0401_6

[30] Otsuka, Y. (2008) The COPE Inventory: A theoretically based coping questionnaire. Hiroshima Psychological research, 8, 121-128.

[31] Otsuka, Y., Sasaki, T., Iwasaki, K. and Mori, I. (2009) Working hours, coping skills, and psychological health in Japanese daytime workers. Industrial Health, 47, 22-32. http://dx.doi.org/10.2486/indhealth.47.22

[32] Kataoka, M., Iwamitsu, Y., Kawakami, Y., Matsuzaka, Y., Okawa, M. and Takigawa, K. (2003) The relationship among mental health, work situation, and work satisfaction for research associates at college of nursing. Journal of Nursing, Shiga University of Medical Science, 2, 3545.

[33] Kataoka, M., Ozawa, K., Ichie, K., Kumasaka, T. and Iwamitsu, Y. (2009) Relationship among mental Health, coping, and job satisfaction in research associates at nursing college. Japanese Bulletin of Social Psychiatry, 18, 74-83.

[34] Karasek, R.A. (1979) Job demands, job decision latitude, and mental strain: Implications for job redesign. Administrative Science Quarterly, 24, 285-307. http://dx.doi.org/10.2307/2392498

[35] Yasumi, K., Kageyama, J., Saito, K., Michimata, N. and Kato, M. (2009) Survey targeting teaching staff and students regarding stress-From data of the 4 year period since the national universities were incorporated. Campus Health, 46, 100-105.

[36] Lazarus, R.S. (1993) From psychological stress to the emotions: A history of changing outlooks. Annual Review of Psychology, 44, 1-21. http://dx.doi.org/10.1146/annurev.ps.44.020193.000245

[37] Perlin, L.I. and Schooler, C. (1978) The structure of coping. Journal of Health and Social Behavior, 19, 2-21. http://dx.doi.org/10.2307/2136319

[38] Tominaga, M. and Kogawa, T. (2007) The effect of coping style and occupational stressors on psychological distress of information technology professionals in Japan. Bulletin of Health Sciences Hirosaki, 6, 1-9. 